\title{
É PÓS-METAFÍSICA A TRANSFORMAÇÃO APELIANA DA ÉTICA DE KANT?
}

\begin{abstract}
SÍNTESE - Mesmo que se possa ponderar que em Apel não exista uma metafisica no sentido tradicional do termo, há que se considerar que existem aí elementos típicos de uma postura metafisica. Dessa forma, a transformação semiótico-transcendental levada adiante por Apel em relação à ética kantiana não se constitui em uma transformaçăo pós-metafisica no sentido estrito do termo, pois, se por um lado Apel recusa os pressupostos metafísicos presentes na ética de Kant, por outro se vale de elementos que, de alguma maneira, sempre estiveram na base da tradição da metafisica ocidental. A novidade é que esses pressupostos aparecem agora reconstruidos a partir de um prisma semióticotranscendental. Apel opera assim uma espécie de novo deslocamento dentro do deslocamento já efetuado por Kant em relação à metafísica tradicional.

PALAVRAS-CHAVE - Apel, Metafisica, Kant, transformação, semiótica transcendental.
\end{abstract}

ABSTRACT - Even if one may ponder that in Apel there is no metaphysics in the traditional meaning of the word, one should consider that there are typical elements of a metaphysical posture. In this way, the semiotic-transcendental transformation conducted by Apel concerning kantian ethics does not constitute a postmetaphysical transformation in the strict meaning of the word, for, if on one hand Apel refuses the metaphysical assumptions present in Kant's ethics, on the other hand he helps himself with the elements which, in scme way, always have been at the base of the tradition of western metaphysics. The novelty is that these assumptions now appear rebuit from a semiotictranscendental prism. Thus Apel operates a kind of new displacement within the displacement already effected by Kant concerning traditional metaphysics.

KEY WORDS - Apel, metaphysic, kant, transformation, semiotic-transcendental

\section{Introdução}

Uma das principais acusações feita por Apel à ética kantiana é a de que as questões fundamentais desta têm por base um horizonte metafísico. Isso o motiva a operar em relação à mesma uma transformação que, a partir de um prisma pósmetafísico, dê conta de seus limites. Porém, em que pese o esforço apeliano para ultrapassar tal horizonte, entendemos que o mesmo reaparece no pensamento e na ética do próprio Apel. Mesmo que se possa ponderar que em Apel não exista uma metafísica no sentido tradicional do termo, há que se considerar que existem aí elementos típicos de uma postura metafísica.

* Professor do Curso de Filosofia da Universidade de Passo Fundo, Rio Grande do Sul.

\begin{tabular}{|l|l|l|l|l|l|}
\hline VERITAS & Porto Alegre & v. 43 & $\mathrm{n}^{2} 4$ & Dezembro 1998 & p. 969-978 \\
\hline
\end{tabular}


É possivel, pois, identificar-se alguns aspectos que permitem afirmar a presença de uma renovação da metafísica na filosofia de Apel. Dentre eles, destacamse a determinação semiótica da transcendentalidade, ou seja, a defesa de um nível de transcendentalidade, a referência a uma esfera de idealidade - a comunidade ideal de comunicação - uma renovação do paradigma da Prima philosophia, o desenvolvimento de um método de fundamentação última, que se vincula tanto ao conhecimento quanto à ação, uma certa reedição da idéia de fundo de uma racionalidade unificante - própria à grande filosofia - e a busca de legitimação dos pressupostos últimos do saber e do agir com sentido.

\section{I}

Amparado na idéia de razão como razão argumentativa, Apel procura enquadrar-se no âmbito de uma filosofia pós-metafísica, o que, no seu entender, permite identificar a própria ética de Kant como limitada, por amparar-se em pressupostos metafísicos. Apesar de tal crítica, Apel mantém-se ligado à tradição kantiana na medida em que recorre a uma transcendentalidade renovada. Por isso, recusa uma saída via ética substancial, conforme o modelo dos atuais neo-hegelianos, ou subjetivista, aos moldes do racionalismo crítico, do emotivismo, etc. Em outros termos, recusa tanto um falibilismo radical quanto uma ontologia, tendo, assim, de permanecer ainda dentro do horizonte do deslocamento da metafísica operado por Kant em relação à tradição.

A intenção de Apel, ao renovar a dimensão da transcendentalidade, não é apenas reabilitar a racionalidade teórica mas, sobretudo, a racionalidade prática, desfazendo, assim, o abismo instalado entre ambas. Para tanto, Apel distancia-se em parte da perspectiva kantiana, aproximando-se de Peirce e procurando, como este, desfazer a separação entre razão teórica e razão prática. ${ }^{1}$ Esse aspecto fica claro principalmente quando recorre às condições de possibilidade para explicar o conhecer e o agir, ou seja, as coisas são explicadas através da recorrência às condições de possibilidade das próprias coisas. Aí aparece a mesma exigência fundamental de toda explicação metafísica, ou seja, a eliminação da condição de possibilidade de um dado objeto implicaria a eliminação do próprio objeto como tal (Pinto, 1995, p. 20).

Apel segue Kant na medida em que aceita seu pensamento se vincula à esfera da transcendentalidade. Tal esfera, no entanto, na perspectiva apeliana, é renovada lingüisticamente e por isso passa a referir-se ao âmbito das pretensões universais de validade. A transcendentalidade assume um caráter linguiústico e semiótico, caráter este que está na base da argumentação intersubjetivo-racional. Apel, a nosso ver, por meio do a priori do jogo de linguagem transcendental, reúne as condições para demonstrar novamente a possibilidade e a necessidade do status teórico da metafísica como filosofia primeira. A semiótica transcendental assume esse papel, não sendo, neste sentido, uma filosofia pós-metafísica, mas um novo marco filosófico, um novo paradigma de Prima philosophia, pois falar em filosofia

1 A esse respeito ver do autor A transformaçăo apeliana da ética de Kant. Passo Fundo: Ediupf, 1998. 
primeira é falar em metafísica. Dessa maneira, o próprio esforço de estabelecer um novo paradigma de Prima philosophia não deveria ser entendido como um esforço genuinamente metafísico?

$\mathrm{Na}$ perspectiva da pragmática transcendental, as condições de possibilidade da práxis argumentativa são descobertas por estrita reflexão, porque se trata de descobrir e explicitar o que já está contido, necessariamente, na práxis argumentativa. Tais condições são, pois, intranscendíveis, o que significa que não podem ser contestadas sem que se caia em contradição; sua dedução direta implica petição de princípin uma vez que toda prova já tem de pressupor essas condiçōes. Ora, em Apel, como já foi indicado, a própria argumentação nos obriga a reconhecer um conjunto de regras que, em si mesmas, já são normas éticas.

O problema de Kant, segundo Apel, foi não ter proposto um modelo alternativo de fundamentação que fosse próprio para a ética. ${ }^{2}$ Por essa razão, Apel vai falar de um déficit de fundamentação na ética kantiana, ou seja, ele substitui a fundamentação por um fato da razão não demonstrável - porque aceitar fundamentação para a ética significaria, para Kant, adotar o modelo de fundamentação próprio ao conhecimento - nem fundamentado de alguma outra maneira, quer direta, quer indiretamente. Para a pragmática transcendental, o que deve ser fundamentado transcendentalmente é aquilo que já deve estar sempre pressuposto em toda argumentação e que possui caráter intersubjetivo.

A pragmática transcendental pretende, então, vincular a intersubjetividade a um modelo de fundamentação de caráter reflexivo. Na verdade, Apel vai operar aqui uma renovação da tradição metafísica ocidental, o que significa que 0 aspecto novo trazido por sua filosofia está na sua utilização de argumentos reflexivos no âmbito de uma transformação da filosofia transcendental. Essa, agora, pretende repensar a unidade entre filosofia teórica e filosofia prática e se constituir em uma "teoria transcendental da intersubjetividade levantando a pretensão de superar a ontologia tradicional, a teoria moderna do conhecimento e a filosofia analítica contemporânea da linguagem"' (Oliveira, 1996, p. 370).

A questão que, no entanto, voita a ser colocada é a seguinte: É possível tal empreendimento fora do âmbito de uma metafísica? Os argumentos último a partir dos quais Apel sustenta sua transformação da filosofia e da ética de Kant implicam na aceitação de pressupostos metafísicos. Nesse sentido, é também, necessariamente metafisica a própria transformação apeliana - pragmático-transcendental da ética de Kant. Assim, a transcendentalidade pragmática, na medida em que se alicerça em um fundamento último, já está reccrrendo a um pressuposto metafísi$\mathrm{co}$, mesmo que reflexivo.

Nosso pressuposto é o de que toda transcendentalidade - inclusive a transcendentalidade renovada de Apel - é metafísica, mesmo que se trate de uma nova metafísica, a da comunicação; o mesmo argumento vale também para o conceito de racionalidade: o conceito de razão implica metafísica. Apel fala numa renovação do principio-lógos descoberto pelos gregos, que possui um caráter intranscen-

2 Kant, para Apel, por abandonar a idéia de uma fundamentaçāo da ética, obrigou-se a recorrer ao conceito metafisico de reino dos fins para pensar a autonomia da vontade como ratio essendi da lei moral, tentando, assim, dar conta desse aspecto. 
dível e tem como critério a contradição performativa. Isso significa que Apel deixa de lado a racionalidade lógico-formal e o modelo dedutivo-hipotético de fundamentação, criando um modelo renovado, ou seja, o da racionalidade comunicativa e da fundamentação reflexiva. Tal modelo de fundamentação tem como pretensão a tematização das condições de possibilidade, vistas como intranscendíveis em toda e qualquer argumentação.

\section{II}

Fica claro que Apel opera um deslocamento em relação à metafísica tradicional, o que ocorre na medida em que se nega a engendrar uma explicação ontológico-cosmológica do mundo; ao invés disso, propõe a busca de uma "autocertificação da razão argumentativa" (Apel, 1993a, p. 317). Dessa maneira, a idéia de fundamentação não se inscreve mais na esfera do ser ou da consciência, mas no âmbito da linguagem - da argumentação com suas pretensões de validade. A ordem metafísica do logos e do ser agora se converte em chave da teleologia lingüística (Conill, 1988, p. 258); o deslocamento operado em relação à metafísica tradicional se dá do ser ou da consciência em direção à práxis lingüística. Apesar disso, a exigência clássica volta, ou seja, trata-se do postulado de uma fundamentação última, da mesma forma que de uma entidade ideal, ainda que esta se apresente travestida com nova roupagem; agora, ela aparece sob a "forma das condições universais a priori e não contingentes da razão argumentativa" (Pinto, 1995, p. 22).

Com efeito, a semiótica transcendental, ao deixar de lado a função de representação das proposições, adota como orientação a dupla estrutura proposicionalperformativa do discurso humano. Desta forma, no discurso, é assumida a tridimensionalidade dos signos e da linguagem, nele se articulando a pragmática e a hermenêutica, que devem levar em conta o sujeito em sua situação vital. Assim, a semiótica transcendental se constitui em um paradigma de racionalidade comunicativa, no qual o saber reflexivo assume a forma de proposições auto-referenciais e com pretensão universal de validade. Além disso, a semiótica transcendental pode ser entenđida como um modelo teórico e prático do pensamento filosófico na medida em que oferece uma instância intersubjetiva para o conhecimento verdadeiro e as bases para a responsabilidade solidária, tendo como pressuposto a comunidade ideal de comunicação.

A partir desse prisma, Apel vai defender a idéia de uma fundamentação última, que tem origem no próprio núcleo central do pensamento metafísico. Como foi mostrado, ele adota tal idéia, embora lhe negue uma conotação metafísica. Nesse sentido, Apel tem de rebater as críticas que o acusam de incorrer nos mesmos problemas que rondam os modelos de fundamentação próprios à metafísica tradicional; ele refuta também o trilema de Münchhausen, considerando-o somente possível pela abstração da dimensão pragmática do uso da linguagem. Porém, somente na medida em que o sujeito do conhecimento e da argumentação for abstraído, pode ficar caracterizado o recurso à evidência como interrupção do procedimento de fundamentação. Ocorre que a perspectiva sintático-semântica separa a linguagem do mundo da vida, reduzindo, desse modo, o processo de 
fundamentação à dedução. Assim, o mérito de Apel aqui reside em ter superado tal separação, baseando-se em um conceito reflexivo de fundamentação.

Tal conceito é fundamental para a ética na medida em que seu procedimento vale para a fundamentação de normas. Isso significa que, como reflexivamente fundamentado, vale aquilo que não se pode negar, sem que se incorra em contradição performativa, e que não se pode fundamentar dedutivamente, sem que se aceite sua validade como já pressuposta. Apel opera, pois, com um modelo reflexivo de fundamentação de normas. Por isso, a reflexão sobre as condições de possibilidade da práxis argumentativa, isto é, da práxis comunicativa, mostra que, em toda argumentação, nós, já desde sempre, temos de reconhecer certas regras que já são normas éticas (Souza, 1994, p. 173). A racionalidade prática possui aqui também uma dimensão deontológica, presente pelo fato de haver um telos imanente à compreensão lingüística, o que significa que a reflexão sobre a estrutura da argumentação e do entendimento tem condições de explicitar a validade de certas sentenças normativas de caráter universal.

Contra a crítica da perspectiva falibilista à fundamentação, Apel observa que a dúvida e a crítica só possuem sentido se se recorrer a evidências paradigmáticas. A reflexão pragmático-transcendental sobre as condições de possibilidade de uma argumentação crítica precisa ter como base o jogo transcendental de linguagem - o jogo argumentativo. Trata-se aqui de um método de fundamentação - não dedutivo - pelo qual é possivel aceder-se às evidências paradigmáticas, que são aquelas que não podem ser postas em dúvida sem autocontradição e que não podem ser fundamentadas dedutivamente sem que se pressuponham já a si mesmas.

Por isso, essas evidências últimas não podem ser negadas sem autocontradição, nem podem ser fundadas sem petitio principii. Trata-se dos pressupostos pragmáticos da argumentação, que desde sempre precisam já ser reconhecidos para que o jogo lingüístico da argumentação possa ter sentido. Isso permite que se fale também no nivel ideal - normativo - do jogo transcendental de linguagem, e em suas evidências paradigmáticas, bem como dos pressupostos de uma fundamentação última da ética. Apel obteria, assim, a partir da renovação do conceito de fundamentação, um duplo ganho para sua ética: por um lado, evitaria cair no mesmo problema que identifica em Kant, ou seja, em um déficit de fundamentação; por outro, refutaria, vigorosamente, toda e qualquer possibilidade de relativismo e subjetivismo éticos.

Porém, mesmo que se pondere que não há em Apel uma metafísica no sentido tradicional do termo, há que se considerar, como já foi observado, que existem aí elementos típicos de uma postura metafísica. Outro desses elementos é a referência a uma esfera de idealidade - a comunidade ideal de comunicação - elemento que fundamenta de forma transcendental a realidade e que, em Apel, funciona como um pressuposto contrafático justamente para evitar uma possível pecha de metafísica. Como o próprio Apel afirma, a comunidade ideal é, ao mesmo tempo, "postulado e antecipação contrafática" (Apel, 1993a, p. 322), além de corresponder à "estrutura essencial da instituição do argumentar" (Apel, 1987a, p. 273). 
Com êfeito, a fundamentação última, de caráter transcendental, ainda está filiada àquilo que o próprio Apel e sua proposta de fundamentação pretendem rejeitar, ou seja, à metafísica. Apel admite em tal fundamentação a existência de uma entidade ideal supra-sensivel, a "comunidade infinita e ideal, a qual unicamente pode ser o sujeito transcendental de um consenso definitivo sobre o verdadeiro e normativamente correto" (Apel, 1993a, p. 322). Esta comunidade de comunicação ideal é caracterizada como a "metainstituição de todas as instituições humanas possiveis” (Apel, 1987, p. 296).

\section{III}

Outro aspecto que indica para um horizonte metafísico no pensamento de Apel é o fato dele promover uma espécie de reedição da idéia de fundo da grande filosofia, ou seja, o projeto de uma racionalidade que indica o lugar próprio dos saberes do sistema - racionalidade estratégica - e do mundo da vida - racionalidade comunicativa. Essa reedição é explicitada por Apel ao reconhecer sua intenção, na esteira de Kant, de reabilitar a racionalidade prática, ou seja, ele procura reabilitar aqui um duplo estatuto para a metafísica: teórico, via hermenêutica transcendental; prático, via pragmática transcendental.

Sem dúvida, uma das maiores, ou a maior contribuição da pragmática transcendental de Apel, é ter retomado a idéia da filosofia enquanto saber dos saberes. Em outros termos, trata-se de um saber ao qual compete a "legitimação dos pressupostos últimos de todo saber e com isso de si mesmo" (Oliveira, 1996, p. 418). Isso se torna possível através de "uma demonstração reflexiva enquanto explicitação das condições de possibilidade da práxis comunicativa pela mediação da contradição performativa" (idem). Além da legitimação dos pressupostos últimos de todo saber, a pragmática transcendental pretende ser, também, tematização dos pressupostos últimos do agir humano com sentido.

A pragmática transcendental é uma tentativa de unidade entre racionalidade teórica e racionalidade prática na medida em que os mesmos pressupostos valem para a legitimação tanto de uma esfera quanto de outra. A racionalidade comunicativa é unificante por possuir uma estrutura formal, universal, que agrega um momento de incondicionalidade; é a formalidade lógico-pragmática que possibilita a Apel defender a unidade da razão nas distintas pretensões de validade. Ora, como pode Apel recusar que se trate aqui de um horizonte metafísico se a própria idéia de filosofia é aí identificada com os pressupostos últimos do conhecer e do agir?

Aliado a esta preocupação está o esforço apeliano de elaboração de uma teoria dos tipos de racionalidade, o que significa que, ao mesmo tempo em que busca unificar racionalidade prática e racionalidade teórica, distingue tipos de racionalidade com o intuito de assegurar um estatuto próprio a cada um deles. Apel, no entanto, deixa claro que a racionalidade comunicativa - prática - é o tipo originário, em referência à qual todo o agir humano pode e deve ser pensado. 
Em relação a um outro aspecto fundamental da crítica à ética de Kant, ou seja, o caráter metafísico do factum da razão, Apel vai tentar superá-lo, aplicando a reflexão transcendental a um fato lingüístico, isto é, ao fato da argumentação. Toma como ponto de partida o caráter intersubjetivo presente em tal fato uma vez que este é incontestável e irretrocedível, pois quem pretender eliminá-lo racionalmente deverá se valer de argumentos, emitindo automaticamente pretensões de validade. Como o fato da razão não se sustenta mais na consciência moral, mas nas estruturas pragmáticas inerentes à linguagem humana, pode-se observar que Apel se desloca dentro do âmbito de uma metafísica da pragmática da linguagem.

Com essa pretensão de reconstruir o fato da razão kantiano a partir da crítica do sentido, Apel julga possivel, então, renunciar a todo e qualquer pressuposto metafísico. No entanto, a perspectiva apeliana não acaba aqui introduzindo, com o fato da argumentação, precisamente um novo pressuposto metafísico? O procedimento de Apel - ao transformar a pergunta kantiana pelas condições de possibilidade do conhecimento na pergunta pelas condições do sentido da argumentação não se mantém análogo à atitude de Kant, apenas com a transformação da base metafísica da consciência em uma metafísica da comunicação?

Se não bastasse, os pressupostos da racionalidade, na medida em que estão presentes em toda a argumentação com sentido, agora são os mesmos tanto para o âmbito teórico quanto para o âmbito prático da razão. Ora, isso nos leva a indicar que tais pressupostos são próprios de uma nova metafísica, não reconhecida por Apel por causa de sua obstinação em negar o pensamento metafísico.

No que se refere especificamente à ética, isso traz outra conseqüência: em relação à fundamentação da ética, implica, inicialmente, a distinção de uma parte A em relação a uma parte B. Na parte A, vai ocorrer a ascensão do fato da argumentação às condições de sentido desse, dentre as quais é possivel descobrir-se um princípio categórico que requer e possibilita que tal ética tenha um caráter universal. Tal princípio moral se constitui numa concretização de caráter dialógico do imperativo categórico e, como ocorria em Kant, Apel pretende manter seu estatuto transcendental, apoiando-se sobre um ponto supremo. Este ponto, no entanto, não consiste mais na unidade da consciência do objeto e da autoconsciência; constitui-se, agora, na unidade da interpretação produzida entre sujeitos, com o que o ponto supremo não é mais o eu da apercepção transcendental, mas um nós transcendental.

É este nós irretrocedivel que justifica a existência de um princípio moral que prescreve, de forma categórica, o reconhecimento recíproco dos interlocutores de uma argumentação. Como se pode observar, a estrutura da argumentação de Apel aqui é análoga à de Kant; a diferença está, apenas, no novo estatuto concedido à transcendentalidade. Parece evidente, contudo, que o fato de reformular tal estatuto não elimina seu caráter metafísico, tão somente o renova.

Essa transformação da estrutura transcendental clássica vai permitir a Apel defender que a validez moral das normas não pode fundamentar-se nem no solipsismo metódico - risco que Apel vê Kant correr - nem no fato de sua mera aceitação, ou seja, num decisionismo ético, o grande sofisma do liberalismo ético con- 
temporâneo. A aceitação das regras do jogo de uma comunidade crítica de comunicação emana do fato da argumentação e se constitui, diferentemente, em condição de possibilidade e validez da comprovação de fatos, não se reduzindo a um fato empírico. Mesmo que se ampare em uma pragmática da linguagem, aqui aparece como suporte da transcendentalidade a metafísica da comunicação.

Outra idéia contestada por Apel, decorrente já da crítica à concepção kantiana do conhecimento, é a sustentação metafísica da idéia de liberdade. Ao rejeitar a idéia dos dois mundos, Apel rejeita também o fundamento da liberdade, que advém da causalidade de um ser racional, isto é, do fato de o homem possuir uma causalidade oriunda de si mesmo, enquanto parte do mundo inteligível. Apel não admite tal separação por considerar que o fundamento do agir não depende da possibilidade de uma causalidade do ser racional, mas do reconhecimento de certas pretensões de validade por parte de uma determinada comunidade de comunicação. Aqui volta a crítica feita anteriormente a Apel acerca do problema da metafísica, ou seja, ele recusa a metafísica da liberdade - da causalidade de um ser racional, inteligivel - mas, na medida em que sua ética se sustenta em um nivel de transcendentalidade - 0 das pretensões de validade - coloca uma nova metafísica na base da mesma, a saber, uma metafísica da linguagem ou da comunicação, como antes foi denominada.

\section{V}

A partir das considerações feitas aqui, somente em um sentido Apel pode falar de filosofia pós-metafísica ou de uma transformação pós-metafísica da ética de Kant, ou seja, somente na medida em que recria as bases da metafísica de matiz kantiana, o que significa que ele leva a sério as críticas de Heidegger e de Wittgenstein à metafísica. O esforço apeliano, no entanto, continua sendo metafísico, pois ele se vale da estrutura conceitual da metafísica para empreender uma transformação na concepção metafísica de Kant, o que significa que ele não sai do âmbito da transcendentalidade, mas apenas o renova.

Assim, a transformação semiótico-transcendental de Kant e, mais precisamente, de sua ética, ao mesmo tempo em que amplia ou renova a dimensão da transcendentalidade, não abandona, pura e simplesmente, a perspectiva da metafísica, mas o faz, isto sim, a partir de um novo prisma metafísico. Apel não opera, portanto, uma transformação pós-metafísica da ética de Kant, como pretende em seu principal trabalho sobre esse tema (Apel, 1993). Essa transformação só pode ser entendida como pós-metafísica no sentido de procurar ir além dos pressupostos da metafísica com a qual Kant dá sustentação à sua ética. Trata-se da transformação de um tipo de metafísica. Com isso, conclui-se que Apel se distancia da metafísica kantiana do conhecimento e da ação, mas ao preço de reeditar uma nova metafísica, baseada na pragmática da linguagem. Isso significa que Apel não carece de uma metafísica, mas, sim, de tornar mais conseqüentes os pressupostos metafísicos de sua pragmática transcendental.

A transformação apeliana da ética de Kant é, então, assim entendida aqui: trata-se, sim, de uma transformação, ou seja, de uma transformação semióticotranscendental baseada em Peirce e Wittgenstein, mas não de uma transformação 
pós-metafísica no sentido estrito do termo. Ocorre que, se por um lado Apel recusa os pressupostos metafísicos presentes na ética de Kant - e nesse sentido apenas poder-se-ia falar em uma filosofia pós-metafísica, isto é, na medida em que se trata de uma transformação de pressupostos da metafísica moderna - por outro se vale de elementos que, de alguma maneira sempre estiveram na base da tradição da metafísica ocidental. A novidade é que esses pressupostos aparecem agora reconstruídos a partir de um prisma semiótico-transcendental. Tais pressupostos agora aparecem ínsitos na linguagem. Pode-se afirmar, assim, que Apel opera uma espécie de um novo deslocamento dentro do deslocamento já efetuado por Kant em relação à metafísica tradicional.

Ora, Apel deveria reconhecer que é desta base, ainda filiada à metafísica, que se torna possível sua transformação da ética de Kant, inadequadamente denominada de transformação pós-metafísica. Isso indica que Apel se locomove dentro da esfera não exatamente de um pensamento pós-metafísico - embora assim o reivindique - mas de uma nova metafísica, a da comunicação. ${ }^{3}$

Em suma, Apel busca operar avanços significativos em relação a determinados problemas deixados pela ética de Kant, como é o caso do fato da razão, da idéia dos dois mundos, do problema da fundamentação, de uma ética da responsabilidade, etc. No entanto, o redimensionamento de tais questões se dá não por ele ter abandonado a metafísica, mas, justamente, por ter por base uma nova metafísica, que tem como ponto de sustentação uma transcendentalidade e uma esfera de idealidade renovadas.

Com isso, Apel oferece uma grande contribuição filosófica para o enfrentamento do relativismo e da destranscendentalização que ronda o pensamento contemporâneo, ao mesmo tempo em que dá passos significativos em relação à ética de Kant, principalmente no que diz respeito às dificuldades dessa acerca da historicidade. Além disso, a idéia de fundamentação última, na medida em que demonstra que toda argumentação pressupõe principios éticos, tem um importante papel a desempenhar: ela possibilita, no entender de Apel, superar tanto o déficit de fundamentação da ética kantiana quanto a negação de toda e qualquer fundamentação defendida por diferentes posturas filosóficas contemporâneas e que, muitas vezes, implica em relativismo ético.

\section{Referências bibliográficas}

ALBERT, H. Tratado da razão crítica. Rio de Janeiro: tempo Brasileiro, 1976.

APEL, K.-O . La transformación de la filosofia (v. I e II). Madrid: Taurus, 1985.

- "Le sémiotique transcendentale et les paradigmes de la Prima philosofia". In.: Revue de Métaphisique et Morale" ,. n. 2, avr.juin 1987.

- . "El problema de la fundamentación filosófica úitima desde una pragmática transcendental del lenguaje". In: Estudios Filosoficos, v. 36, n. 102, mayo.-ago. 1987a, p. 251-299.

- "O desafio da crítica total da razão e o programa de uma teoria filosófica dos tipos de racionalidade”. In: Novos Estudos CEBRAP, mar. 1989.

- . "La ética del discurso como ética de la responsabilidad. Una transformación posmetafisica de la ética de Kant”. In: Teonia de la verdad y ética del discurso. Barcelona: Paidós, 1991.

3 Essa denominação devemos a Conill em El crepúsculo de la metafísica, p. 252 ss. Também a denominaremos, por vezes, de metafísica da pragmática da linguagem. 
- Teoria de la verdad y ética del discurso. Barcelona: Paidós, 1991a.

"L'étique du discours comme étique de la responsabilité: une transformation postmétaphysique de l'étique Kantienne". In: Revue de Métaphysique et de morale, n. 4/1993.

- "Fundamentação última não metafísica?"' In.: Dialética e liberdade. Petrópolis: Vozes; Porto

Alegre: Ed. da Universidade, 1993a.

- Semiotica filosofica. Buenos Aires: Aimagesto, 1994.

- Estudos de moral moderna. Petrópolis: Vozes, 1994a.

— . Le logos prope au langage humain. Paris: Ed. de L'éclat, 1994b.

- Discussion et responsabilité. 1, L'Éthique aprés Kant. Paris: Éditions du Cerf, 1996.

ARISTÓTELES. Metafisica. Madrid: Gredos, 1994.

CENCI, A. A transformação apeliana da ética de Kant. Passo Fundo: Ediupf, 1998.

- "Apel e a fundamentação da ética do discurso". In: Critica, Londrina, v. 1, n. 2, jan.-mar. 1996, p. 123-160.

CIRNE LIMA, C. R. V. Sobre a contradição pragmática como fundamentação do sistema. In: Sintese Nova fase, v. 18, n. 55,1991, p. 595-616.

CONNI, J. El crepúsculo de la metafísica. Barcelona: Anthropos, 1988.

- La semiotica transcendental como filosofia primera. In.: Estudios Filosoficos, v. 32, n. 91, set.-dez. 1983, p. 493-516.

CORTINA, A. Razon comunicativa y responsabilidad solidaria. Salamanca: Sígueme, 1988.

DOMINGUES, I. "A questão da fundamentação úitima na filosofia." In: Kriterion, n. 91, jul. 1995, p. 2944.

HABERMAS, J. Teoria de la acción comunicativa: complementos y estudios previos. Madrid: Catedra, 1989.

- Consciência moral e agir comunicativo. Rio de Janeiro: Tempo Brasileiro, 1989a.

HERRERO, X. "A razão kantiana entre o lógos socrático e a pragmática transcendental". In.: Sintese Nova Fase, n. 52, 1991, p. 35-57.

—. "O problema da fundamentação última". In: Kriterion, n. 91, jul. 1995, p. 7-16.

KANT, I. Crítica da razão prática. Lisboa: Ed. 70, s. d.

- Fundamentaçâo da metafísica dos costumes. Lisboa: Ed. 70, s. d.

OLIVEIRA, M. A. Sobre a fundamentação. Porto Alegre: EDIPUCRS, 1993.

- Ética e práxis histórica. São Paulo: Ática, 1995.

- "Reviravolta lingüístico-pragmática na filosofia contemporânea". São Pauio: Loyola, 1986.

PINTO, P. R. M. “O problema da necessidade da fundamentação última não-metafísica em Karl-Otto Apel”. In: Kriterion, n. 91, jul. 1995, p. 17-28.

SOUZA, J. M. A. O argumento pragmático-transcendental e a transformação da filosofia. Porto Alegre: UFRGS, 1994 (dissertação de mestrado). 